\title{
Quince años de la Revista Médica Herediana.
}

Tengo el grato encargo de los Directivos, Profesores y Alumnos de la Facultad de Medicina Alberto Hurtado, de dirigirme a los subscriptores y lectores de la Revista Médica Herediana, Publicación Oficial de la Facultad de Medicina, y comunicarles que celebramos quince años de publicación ininterrumpida, algo difícil e inusual en nuestro medio, mas aún si al esfuerzo de entregar cuatro números al año, el Consejo de Editores se impuso como objetivo mantener altos estándares de calidad para sus publicaciones.

La Revista Médica Herediana fue una de las primeras en implementar el arbitraje editorial o revisión por pares expertos (peer review), lo que ha permitido ocupar un lugar de liderazgo en los que respecta a publicaciones científicas del área biomédica en el Perú y mantenerlo a lo largo de estos quince años.

La revista ha cumplido con los objetivos planteados desde su creación: La difusión de resultados originales de investigación, la educación médica continua y la mejora en la redacción de los artículos científicos.

Nuestra visión de futuro para la Revista Médica Herediana es incrementar la frecuencia de publicación, actualmente es trimestral, en un mediano plazo bimestral y en un horizonte cercano llegar a ser mensual, todo ello con una mayor proporción de artículos científicos originales en cada número y cumpliendo con los estándares de calidad que exigen las publicaciones científicas en la actualidad. Contará además con la publicación de uno o dos suplementos anuales de artículos de nuestros alumnos tanto de postgrado como de pregrado con asesoría, para de esta forma promover en nuestro claustro la publicación de los trabajos de investigación realizados. La revista deberá permanecer en la base LILACS (BIREME) y ser incorporada en otras bases como SciELO y MEDLINE; además podrá ser incorporada a las bases de revistas a texto completo, en la medida de sus posibilidades, con el objetivo de incrementar su difusión y mejorar el impacto; es decir, nuestra Revista deberá ser identificada por los investigadores del área biomédica como la mejor opción para la publicación de sus artículos de investigación original, de esta forma mantendrá el liderazgo nacional y competirá por el liderazgo regional y porque no, en un futuro no muy lejano a nivel global.

Dr. Luis Caravedo Reyes* 